\title{
Topical diltiazem and bethanechol decrease anal sphincter pressure without side effects
}

\author{
E A Carapeti, M A Kamm, B K Evans, R K S Phillips
}

\begin{abstract}
Background-Topical nitrates lower anal sphincter pressure and heal anal fissures, but a majority of patients experience headache. The internal anal sphincter has a calcium dependent mechanism to maintain tone, and also receives an inhibitory extrinsic cholinergic innervation. It may therefore be possible to lower anal sphincter pressure using calcium channel blockers and cholinergic agonists without side effects.

Aims-To investigate the effect of oral and topical calcium channel blockade and a topical cholinomimetic on anal sphincter pressure.

Methods-Three studies were conducted, each involving 10 healthy volunteers. In the first study subjects were given oral 60 mg diltiazem or placebo on separate occasions. They were then given diltiazem once or twice daily for four days. In the second and third studies diltiazem and bethanechol gels of increasing concentration were applied topically to lower anal pressure.
\end{abstract}

Results-A single dose of $60 \mathrm{mg}$ diltiazem lowered the maximum resting anal sphincter pressure (MRP) by a mean of $21 \%$. Once daily diltiazem produced a clinically insignificant effect but a twice daily regimen reduced anal pressure by a mean of $17 \%$. Diltiazem and bethanechol gel produced a dose dependent reduction of the anal pressure; $2 \%$ diltiazem produced a maximal $28 \%$ reduction, and $0.1 \%$ bethanechol a maximal $24 \%$ reduction, the effect lasting three to five hours.

Conclusions-Topical diltiazem and bethanechol substantially reduce anal sphincter pressure for a prolonged period, and represent potential low side effect alternatives to topical nitrates for the treatment of anal fissures.

(Gut 1999;45:719-722)

Keywords: diltiazem; bethanechol; anal sphincter pressure; anal fissures

Physiology, St Mark's

Hospital, Northwick

Park, Watford Road,

Harrow, Middlesex

HA1 3UJ, UK

E A Carapeti

M A Kamm

B K Evans

R K S Phillips

Correspondence to:

Professor Kamm.

Accepted for publication 11 May 1999 relaxation, presented such an opportunity. Topical glyceryl trinitrate (GTN), a nitric oxide donor, has been shown to reduce anal pressure $^{3}$ and heal chronic anal fissures in a majority of patients, ${ }^{45}$ thus becoming a first line treatment. Although effective, treatment with topical GTN is accompanied by the side effect of headache in a large number of patients. It would therefore be advantageous if an alternative therapy for lowering anal pressure could be devised which is equally effective as GTN, but without the side effects.

There are at least two important mechanisms by which this might be achieved. A calcium dependent mechanism is required to maintain internal sphincter smooth muscle tone, and calcium channel blockers cause relaxation of gastrointestinal smooth muscle. ${ }^{67}$ Sublingual nifedipine has been shown to lower the resting anal sphincter pressure in both controls and patients with anal disease, ${ }^{8}$ although the therapeutic effect on these anal conditions was not studied. Oral diltiazem has also been shown to reduce the resting anal pressure. ${ }^{9}$

A second important mechanism involves the sacral parasympathetic cholinergic innervation which is inhibitory to the internal anal sphincter. ${ }^{10}$ Cholinomimetics such as carbachol and bethanechol relax internal anal sphincter smooth muscle in vitro ${ }^{11}$ via muscarinic receptors. ${ }^{12}$

We have explored the possible use of a calcium antagonist and cholinomimetic to lower anal sphincter pressure. We investigated the effect of oral diltiazem against placebo, as well as topical gels containing varying concentrations of diltiazem and bethanechol, on the resting anal sphincter pressure of healthy adult volunteers, with a view to determining the dose-response characteristics of these agents.

\section{Materials and methods}

Three studies were conducted. Ten healthy volunteers with no anorectal disease were recruited for each of the oral and topical diltiazem studies and 10 further volunteers for the bethanechol study. Each subject underwent anal manometry using an eight channel water perfused catheter. A station pull through technique was used to determine the maximum resting anal pressure (MRP); recordings were taken over five minutes until a steady reading was obtained. Anodermal blood flow was measured using a DRT4 laser Doppler flowmeter (Moor Instruments, Devon, UK), and expressed as flux $(\mathrm{ml} / \mathrm{min} / \mathrm{mm} \mathrm{Hg} / 100 \mathrm{ml}$

Abbreviations used in this paper: GTN, glyceryl trinitrate; LAS, lateral internal sphincterotomy; MRP, maximum resting anal sphincter pressure. 
A

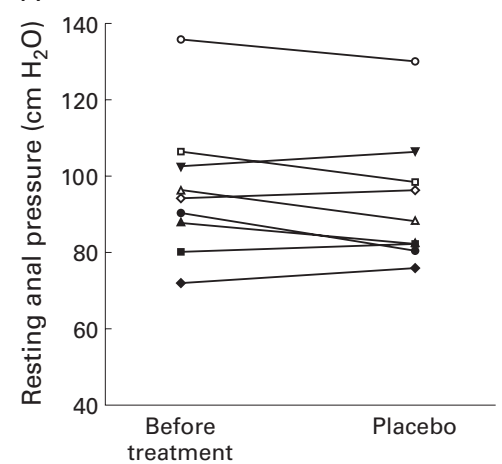

B

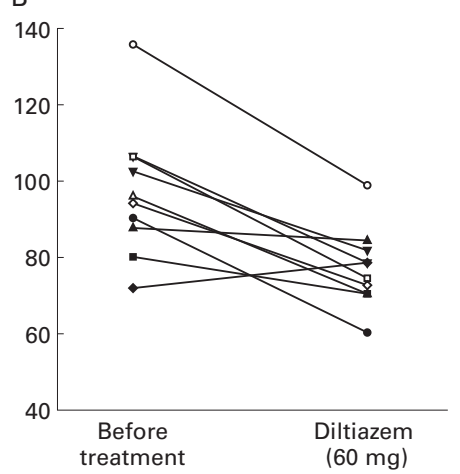

Figure 1 Resting anal sphincter pressure in response to oral placebo * and $60 \mathrm{mg}$ diltiazemt. ${ }^{\star} p=0.4,97$ (17) $v 94$ (16) $\mathrm{cm} \mathrm{H} O$, pre-versus post-treatment mean (SD) maximal resting pressure (MRP) (ANOVA); †p<0.0001, 97 (17) v 77 (11) cm $\mathrm{H}_{2} \mathrm{O}$.

tissue). Ethical approval was obtained from the regional ethical committee.

ORAL DILTIAZEM

Ten subjects (seven men) aged 24-53 years (median 44) were studied. All subjects were given a placebo tablet or $60 \mathrm{mg}$ diltiazem on two separate occasions. Measurements of MRP and anodermal blood flow as well as pulse rate and blood pressure were taken before and one hour after ingestion of each tablet. On a separate occasion, each subject was given 60 $\mathrm{mg}$ diltiazem once daily for four days and measurements taken at the end of this period. Recordings were taken one hour after the morning dose on the fourth day. Further readings were taken before and after a further four days during which the subjects were given 60 mg diltiazem twice daily. Dose and period of administration of diltiazem were based on the known effect in cardiovascular disease and known drug half life (4-6 hours). ${ }^{13}$

TOPICAL DILTIAZEM GEL

Five men and five women aged $20-49$ years (median 30) were studied. Concentrations of $0.1 \%, 0.5 \%, 1 \%, 2 \%, 5 \%$, and $10 \% \mathrm{wt} / \mathrm{vol}$ diltiazem gel and placebo gel were made up. All gels looked identical, and were supplied in identical tubes. A $2.5 \mathrm{~cm}(0.5 \mathrm{ml})$ application of gel provided a measured dose of diltiazem. The gels were formulated to enhance skin permeability. They were applied in a double blind manner; the investigator was given a gel at random by the research assistant who kept the identity of the gel concealed until the end of the study. Gel was applied to the anal margin, not into the anal canal. As with oral dosing, readings of resting anal sphincter pressure and anodermal blood flow were taken before and one hour after each application of gel. If a particular gel produced an effect after one hour, subsequent recordings were made at two hourly intervals thereafter until the readings returned to the baseline pressure recorded prior to the application of the gel.

TOPICAL BETHANECHOL GEL

The 10 subjects (six women) were aged $21-49$ years (median 36). Concentrations of $0.05 \%$, $0.1 \%, 0.5 \%$, and $1 \%$ bethanechol gel, equivalent to doses of $0.2 \mathrm{mg}, 0.4 \mathrm{mg}, 2 \mathrm{mg}$, and $4 \mathrm{mg}$

bethanechol, respectively, were tested. The study was otherwise identical in methodology to the diltiazem gel study described above.

\section{STATISTICAL ANALYSIS}

Statistical analysis was undertaken using analysis of variance (ANOVA) to determine whether there was a significant effect of the dose of diltiazem or bethanechol on sphincter pressure and anodermal blood flow, or whether the variation in measurements observed was due to variation between individuals. Two analyses were performed, looking at blood flow and sphincter pressure separately. A value of $\mathrm{p}<0.05$ was considered significant.

\section{Results}

ORAL DILTIAZEM

There was negligible (3\%) reduction in the mean MRP one hour after placebo $(p=0.4)$. Diltiazem produced a $21 \%$ reduction $(p<0.0001)$ in the mean MRP (fig 1). Once daily diltiazem did not produce a sustained effect, lowering the MRP by $5 \%$ only $(p=0.2)$. There was no reduction in arterial blood pressure with this regimen. The twice daily regimen of diltiazem produced a $17 \%$ reduction in the MRP ( $p=0.0003)$, although in two subjects there was no effect. In addition, although there was only minimal reduction of the mean arterial blood pressure (from 148/88 to $143 / 92$, mean of 10 subjects) with twice daily diltiazem, two subjects did complain of troublesome postural dizziness. These were the only side effects reported. There was no significant difference between the mean anodermal blood flow before and after either dose of diltiazem or placebo.

TOPICAL DILTIAZEM GEL

Placebo produced a $5 \%$ reduction in the MRP (105 (12) versus 100 (12) $\mathrm{cm} \mathrm{H}_{2} \mathrm{O}$, pre- versus post-treatment, mean MRP (SD), $\mathrm{p}=0.19$ ). Diltiazem gel produced a dose dependent reduction of the MRP with concentrations of $1 \%$ and above up to a maximum effect. Two per cent diltiazem gel produced a maximal effect of $28 \%$ reduction in the MRP (105 (12) versus $76(11), p<0.0001)$. Higher concentrations produced no additional effect (fig 2). Repeat measurements showed a sustained inhibition of the resting anal sphincter tone for a period of three to five hours after a single

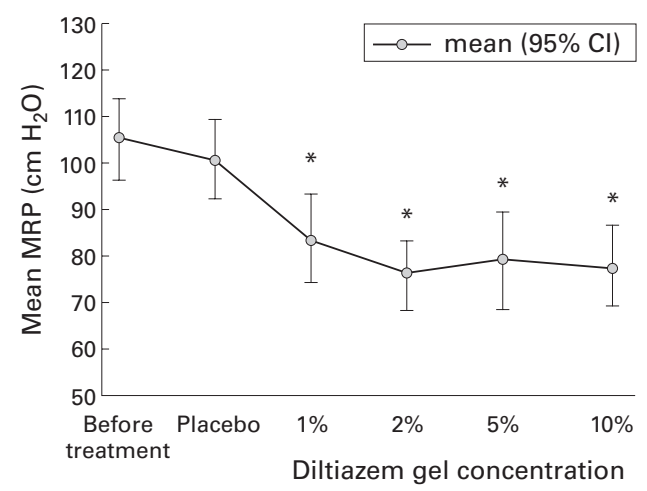

Figure 2 Diltiazem gel dose-response curve in 10 healthy volunteers. ${ }^{\star} p<0.0001$, maximal resting pressure (MRP) compared with pretreatment MRP (ANOVA). 


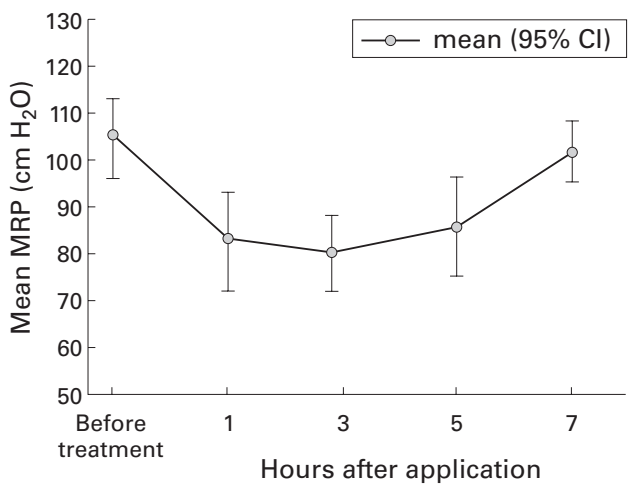

Figure 3 Duration of action of $2 \%$ diltiazem gel following a single application in 10 healthy volunteers. MRP, maximal resting pressure.

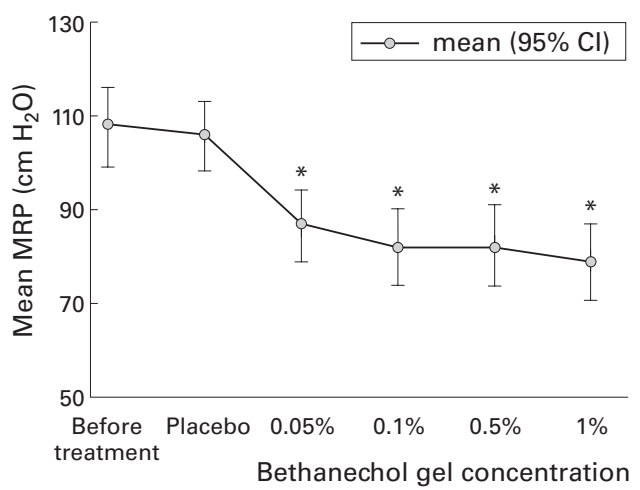

Figure 4 Bethanechol gel dose-response curve in 10 healthy volunteers. ${ }^{*} p<0.0001$, maximal resting pressure $(M R P)$ compared with pretreatment MRP (ANOVA).

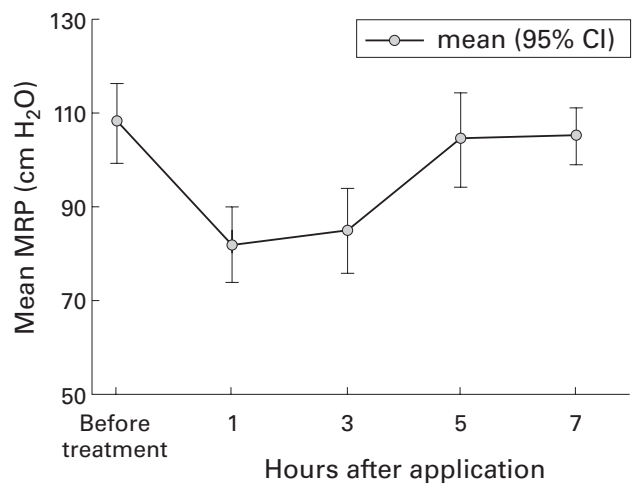

Figure 5 Duration of action of $0.1 \%$ bethanechol gel following single application in 10 healthy volunteers. MRP, maximal resting pressure.

application of $2 \%$ diltiazem gel (fig 3). There was no change in the anodermal blood flow with either placebo or diltiazem, and no local or systemic side effects were reported.

TOPICAL BETHANECHOL GEL

As with diltiazem there was a dose dependent reduction of the MRP with bethanechol gel. Maximal effect was produced by the $0.1 \%$ gel which lowered MRP by $24 \%$ (108 (12) versus 82 (11) $\mathrm{cm} \mathrm{H}_{2} \mathrm{O}$, pre- versus post-treatment, mean MRP (SD), p<0.0001). Higher doses did not produce a greater effect (fig 4). A single application of bethanechol resulted in a decrease in MRP sustained for four (range 3-5) hours (fig 5). No side effects were reported.

\section{Discussion}

Patients with anal fissure have an abnormally high resting anal sphincter pressure. ${ }^{14}$ Healing and relief of symptoms is usually associated with reduction of the maximum resting anal sphincter pressure, ${ }^{15}$ and lateral internal sphincterotomy (LAS) and manual anal dilatation have been used to achieve this. ${ }^{16}{ }^{17}$ However, it is increasingly recognised that there is an appreciable morbidity following these procedures. ${ }^{1}$

In this study we have shown that oral diltiazem, and both topical diltiazem and bethanechol, can lower the resting anal sphincter pressure. Oral diltiazem produced a decrease in the resting anal tone which was not sustained with a once daily dose; the twice daily regimen produced a moderate anal sphincter relaxation but caused side effects in two subjects. The topical preparations were more effective in lowering anal pressure, and were not associated with side effects, these two features suggesting that they are the preferred mode of administration. We have also determined the optimal doses of these agents (2\% diltiazem gel and $0.1 \%$ bethanechol gel) to achieve sphincter relaxation, and showed a duration of action of several hours. The absence of side effects is presumably due to low systemic absorption of the small doses applied locally.

Topical nitric oxide donors have been used to heal successfully up to two thirds of chronic anal fissures. ${ }^{5}$ However, side effects such as headaches and dizziness are common with nitrates, which may limit their application and reduce patient compliance. In addition, tolerance to nitrates is well recognised ${ }^{18}$ and this may be a problem with their use for treatment of fissures. ${ }^{4}$ Injectable botulinum toxin can also lower resting anal pressure and allow fissure healing ${ }^{19}$ but it is expensive and care needs to be taken with this potentially toxic therapy. This study has shown that topical diltiazem and bethanechol can substantially lower the resting anal pressure for several hours. These new agents should now be considered as low side effect alternatives to nitric oxide donors. Their further evaluation in controlled studies, either separately or in combination as a single topical agent, are now needed to substantiate their value in clinical practice for the treatment of anal fissures.

This work has been published in part in abstract form (Gastroenterology 1998;114:A7). We are grateful to Slaco Pharmaceuticals (UK) Limited for supplying the topical preparations, and to Caroline Dore for statistical advice. E Carapeti is supported by the Robert Luff Foundation.

1 Khubchandani IT, Reed JF. Sequelae of internal sphinctertomy for chronic fissure in ano. Brf Surg 1989;76:431-4. 2 Walker WA, Rothenberger DA, Goldberg SM. Morbidity of internal sphincterotomy for anal fissure and stenosis. Dis Colon Rectum 1985;28:832-5.

3 Loder PB, Kamm MA, Nicholls RJ, et al. "Reversible chemical sphincterotomy" by local application of glyceryl trinitrate. Br 7 Surg 1994;81:1386-9.

4 Watson SJ, Kamm MA, Nicholls RJ, et al. Topical glyceryl trinitrate in the treatment of chronic anal fissure. Br f Surg $1996 ; 83: 771-5$.

5 Lund JN, Scholefield JH. A randomised, prospective, double-blind, placebo-controlled trial of glyceryl trinitrate
ointment in treatment of anal fissure. Lancet 1997;349:1114. 
6 Staneva-Stoytcheva D, Venkova K. Effects of the calcium antagonists diltiazem, verapamil and nitrendipine on the contractile responses of guinea-pig isolated ileum to electrical stimulation or carbachol. F Pharm Pharmaco 1992;44:321-5

7 Morales-Olivas FJ, Cortijo J, Esplugues JV, et al. Effect of verapamil and diltiazem on isolated gastro-oesophagea

8 Chhincter of the rat. F Pharm Pharmacol 1985;37:208-9. Chrysos E, Xynos E, Tzovaras G, et al. Effect of nifedipin
on rectoanal motility. Dis Colon Rectum 1996;39:212-16.

9 Jonard P, Essamri B. Diltiazem and internal anal sphincter. Lancet 1987;1:754

10 Frenckner B, Ihre T. Influence of autonomic nerves on the internal and sphincter in man. Gut 1976;17:306-12.

11 Burleigh DE, D'Mello A, Parks AG. Responses of isolated human internal anal sphincter to drugs and electrical field stimulation. Gastroenterology 1979;77:484-90.

12 O'Kelly TJ, Brading A, Mortensen NJ. In vitro response of the human anal canal longitudinal muscle layer to cholinergic and adron ter specialization. Br F Surg 1993;80:1337-41.
13 Reynolds J, Parfitt K, eds. Antihypertensive agents: diltiazem hydrochloride. In: Martindale: the extra pharmacodiltiazem hydrochloride. In: Martindale: the extra pharma

14 Arabi Y, Alexander-Williams J, Keighley MR. Anal pressures in hemorrhoids and anal fissure. Am $\mathcal{f}$ Surg 1977; 134:608-10

15 Rosen L, Abel ME, Gordon PH, et al. Practice parameters for the management of anal fissure. The Standards Task Force, American Society of Colon and Rectal Surgeons. Dis Colon Rectum 1992;35:206-8.

16 MacDonald A, Smith A, McNeill AD, et al. Manual dilatation of the anus. Br F Surg 1992;79:1381-2.

17 Cerdan FJ, Ruiz de Leon A, Azpiroz F, et al. Anal sphincteric pressure in fissure-in-ano before and after lateral internal sphincterotomy. Dis Colon Rectum 1982;25. 198-201.

18 Mangione NJ, Glasser SP. Phenomenon of nitrate tolerance. Am Heart F 1994;128:137-46.

19 Maria G, Cassetta E, Gui D, et al. A comparison of botulinum toxin and saline for the treatment of chronic anal fissure. N Engl f Med 1998;338:217-20. 